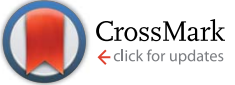

Cite this: RSC Adv., 2016, 6, 8015

\title{
Sinter-resistant gold nanoparticles encapsulated by zeolite nanoshell for oxidation of cyclohexane $\uparrow$
}

\begin{abstract}
Shilpi Saxena, t $^{a}$ Rupesh Singh, $\star^{a}$ Raj Ganesh S. Pala ${ }^{a b}$ and Sri Sivakumar*abc
A large surface-to-volume ratio is a prerequisite for highly effective heterogeneous catalysts. Making catalysts in the form of nanoparticles provides a good way to realize this aim. However, agglomeration of such nanoparticles during the preparation and catalytic reaction remains a formidable problem. In the present work we have synthesized gold nanoparticles-coated with different zeolites, ZSM-5 and MCM22, by hydrothermal route. The method adopted is generic where gold nanoparticles were firstly encapsulated by silica utilizing Stober's process and further these silica coated gold nanoparticles are transformed into Au@MCM-22 and Au@ZSM-5 by modified hydrothermal route. The sinter resistant gold nanoparticle core encapsulated by zeolitic nanoshell showed enhanced conversion for the test reaction of oxidation of cyclohexane to KA-oil, which is an important intermediate in the production of nylon- 6 and nylon-6,6. The nano-capsules act as bifunctional catalyst, with the nanoparticles prevented from agglomeration during synthesis or catalytic applications, and the zeolitic-shell enhanced conversion and reusability of the nano-catalyst.
\end{abstract}

Received 7th October 2015

Accepted 7th January 2016

DOI: $10.1039 / \mathrm{c} 5 \mathrm{ra} 20734 \mathrm{~g}$

www.rsc.org/advances

\section{Introduction}

Nanocatalysts have distinct activity and selectivity, which can be achieved by controlling their size, shape, surface composition, and electronic structure. ${ }^{1-4}$ In particular, gold nanoparticles possess unique catalytic properties when they are supported on metal oxides/carbon and are utilized for various reactions such as $\mathrm{CO}$ oxidation, ${ }^{5,6}$ acetylene hydrochlorination, ${ }^{7}$ hydrogenation, ${ }^{8}$ selective oxidation, ${ }^{9}$ hydroamination ${ }^{10}$ and epoxidation. ${ }^{11}$ However, they may suffer from sintering and subsequent loss in activity due to harsh reactions conditions ${ }^{12}$ (e.g. high temperature, pressure, solvents etc.). This can be circumvented by encapsulating the gold nanoparticles with different shell materials such as silica, ${ }^{13,14}$ mesoporous carbon, ${ }^{15}$ and polymer shell. ${ }^{16}$ Although such approaches decrease sintering, the protective shell does not augment the product selectivity of the composite "nanoparticle core"-"protective shell" catalysts.

Towards this goal, the present work explores and demonstrates the feasibility of structured encapsulants with well-

\footnotetext{
${ }^{a}$ Department of Chemical Engineering, Indian Institute of Technology, Kanpur, UP 208016, India.E-mail: rpala@iitk.ac.in; srisiva@iitk.ac.in

${ }^{b}$ Material Science Programme, Indian Institute of Technology Kanpur, UP208016, India

${ }^{c} D S T$ Unit of Soft Nanofabrication, Centre for Environmental Science \& Engineering, Indian Institute of Technology Kanpur, UP 208016, India

$\dagger$ Electronic supplementary information (ESI) available: Characterization techniques-TEM images, SEM images, UV-vis spectra, SAED pattern, $\mathrm{NH}_{3}$-TPD profiles, and XRD. See DOI: 10.1039/c5ra20734g

$\$$ These authors have contributed equally.
}

defined pores to suppress sintering of encapsulated nanoparticles. While this general approach can be validated by many reactions, we investigate the oxidation of cyclohexane as its product KA-oil (a mixture of ketone and alcohol) is an important intermediate in the production of nylon-6 and nylon-6,6. ${ }^{17}$ Among the materials that have well defined pore structure, ${ }^{18}$ zeolites have found wide applicability in oxidation of cyclohexane. While doping metal ions in zeolites (e.g. Ce-MCM-41, ${ }^{19}$ Ti-MCM-41, ${ }^{17} \mathrm{Cu}(\mathrm{I})-\mathrm{ZSM}-5,{ }^{20}$ and Cr-MCM-41 (ref. 21)) provides a strategy for sinter-resistant cyclohexane oxidation catalysts, such an approach suffers from leaching of metal ions. ${ }^{22}$ On the other hand, gold nanoparticles supported on the surface of ZSM5 (ref. 23) has shown good selectivity, but their prolonged usage at high temperatures/pressures may lead to sintering. Additionally, there are few reports available on metal nanoparticles supported on zeolites for other reactions (e.g. hydrodesulfurization, ${ }^{24}$ oxidation $^{25}$ ) and they may also suffer from sintering as there is no engineered barrier between the nanoparticles to prevent sintering. Few reports demonstrate that many $(>50)$ nanoparticles (e.g. $\mathrm{Pt}$ and $\mathrm{Ag})^{26}$ were encapsulated in a single zeolite microcapsule prepared by seed coating technique for alcohol oxidation at $80{ }^{\circ} \mathrm{C}$. However, nanoparticles could undergo agglomeration at higher temperature/pH because of encapsulation of many nanoparticles inside a single zeolite cavity. Similar effect could also be observed with various metal oxides (e.g. $\mathrm{TiO}_{2}, \mathrm{Fe}_{3} \mathrm{O}_{4}$ (ref. 27 and 28)) encapsulated zeolite microcapsule (>50 nanoparticles encapsulated per zeolite capsule). Recently, gold nanoparticles were encapsulated inside silicalite through impregnation of $\mathrm{Au}$ precursor followed by recrystallization. ${ }^{29}$ However, this approach may not be generic to encapsulate multimetallic nanoparticles. 
We propose a general hydrothermal based synthetic strategy to assemble bifunctional catalysts in which a single gold nanoparticle is encapsulated by MCM-22 and ZSM-5 zeolitesnanoshell. The zeolite nanoshells are of uniform shell thickness, morphology, possess high thermal stability and play the dual role of stabilizing the nanoparticles against sintering and their distinct pore structure can facilitate shape selective catalysis. The zeolite nanoshell encapsulating gold nanoparticles were successfully employed for cyclohexane oxidation and these catalysts showed better conversion with increased reusability. The schematic representation for the synthesis of gold nanoparticle encapsulated by MCM-22 or ZSM-5 is presented in Scheme 1 which depicts the synthesis of gold nanoparticle encapsulated by zeolite nanocapsule, by two-step process. First gold nanoparticles prepared by Turkevich method $^{30}$ were coated with silica shell using Stöber method. In the second step, the silica shell on gold particles was converted into zeolites by modified hydrothermal synthesis. We have prepared two different zeolites (MCM-22 and ZSM-5) over gold nanoparticles. This method can be further generalized for encapsulation of different metal/metal oxides with different zeolite shell.

\section{Experimental}

\subsection{Materials}

Sodium aluminate (98\%), hexamethyleneimine (99\%), tetraethyl orthosilicate (98\%), chloroauric acid (99.99\%) were purchased from Sigma Aldrich. Liquor $\mathrm{NH}_{3}(25 \% \mathrm{v} / \mathrm{v})$ and sodium hydroxide were purchased from Merck's chemicals India, trisodium citrate from Fisher Scientific and all the chemicals were used without further purification. Commercial ZSM-5 (com-ZSM-5) was purchased from Alfa Aesar.

\subsection{Preparation of catalyst}

2.2.1 Preparation of gold nanoparticles. Gold nanoparticles were prepared by citrate reduction method. In the typical synthesis procedure, $4 \mathrm{ml}$ of sodium citrate solution (38.8 mM in water) was added into $40 \mathrm{ml}$ of $\mathrm{HAuCl}_{4}$ solution in water $(0.01 \mathrm{mM})$, with continuous stirring at $90{ }^{\circ} \mathrm{C}$ for $10 \mathrm{~min}$ and $20 \mathrm{~min}$ to prepare 20 and $35 \mathrm{~nm}$ size gold nanoparticles,

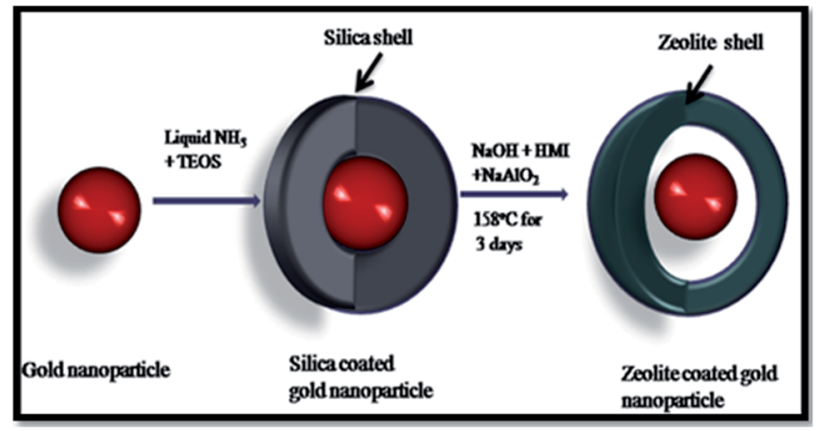

Scheme 1 Schematic representation of synthesis of single gold nanoparticle encapsulated by zeolite-shell. respectively. The synthesized gold nanoparticles were separated out through centrifugation.

2.2.2 Preparation of Au@MCM-22. For silica coating, synthesized gold nanoparticles were first dispersed in $50 \mathrm{ml}$ propane-2-ol, at $40{ }^{\circ} \mathrm{C}$ in round bottom flask. Under stirring condition $2 \mathrm{ml}$ of water along with $1.0 \mathrm{ml}$ of liquor $\mathrm{NH}_{3}$ and $1.21 \mathrm{ml}$ of tetraethyl orthosilicate was added to the flask. The solution was then kept under stirring condition for $2 \mathrm{~h}$ to allow the formation of silica over the gold nanoparticles. In another beaker $0.031 \mathrm{~g}$ of sodium hydroxide was mixed together with $0.34 \mathrm{ml}$ hexamethyleneimine (HMI) and $0.041 \mathrm{~g}$ of sodium aluminate in $8 \mathrm{ml} \mathrm{H}_{2} \mathrm{O}^{31,32}$ The mixture thus obtained was added in silica coated gold nanoparticles. The final mixture was transferred to autoclave and the reaction was carried out at $158{ }^{\circ} \mathrm{C}$ for 3 days. Once the reaction is completed the product was washed with D.I water. The obtained solid product was dried at $100{ }^{\circ} \mathrm{C}$ for 2 hours and ion-exchanged with $1 \mathrm{M} \mathrm{NH}_{4} \mathrm{Cl}$ solution 3 times at $80^{\circ} \mathrm{C}$ for 2 hours, followed by calcinations at $550{ }^{\circ} \mathrm{C}$ for 5 hours.

2.2.3 Preparation of Au@ZSM-5. For silica coating, synthesized gold nanoparticles were first dispersed in $50 \mathrm{ml}$ propane-2-ol, at $40{ }^{\circ} \mathrm{C}$ in round bottom flask. Under stirring condition $2 \mathrm{ml}$ of water along with $15 \mathrm{ml}$ of liquor $\mathrm{NH}_{3}$ and $2.14 \mathrm{ml}$ of tetraethyl orthosilicate was added to the flask. The solution was then kept under stirring condition for $2 \mathrm{~h}$ to allow the formation of silica over the gold nanoparticles. In another beaker $0.053 \mathrm{~g}$ of sodium hydroxide was mixed together with $1.7 \mathrm{ml} \mathrm{HMI}$ and $0.15 \mathrm{~g}$ of sodium aluminate in $15 \mathrm{ml} \mathrm{H}_{2} \mathrm{O}^{33-35}$ The mixture thus obtained was added in silica coated gold nanoparticles. The final mixture was transferred to autoclave and the reaction was carried out at $158{ }^{\circ} \mathrm{C}$ for 3 days. Once the reaction is completed the product was washed with D.I water. The obtained solid product was dried at $100{ }^{\circ} \mathrm{C}$ for 2 hours and ion-exchanged with $1 \mathrm{M} \mathrm{NH}_{4} \mathrm{Cl}$ solution 3 times at $80{ }^{\circ} \mathrm{C}$ for 2 hours, followed by calcinations at $550{ }^{\circ} \mathrm{C}$ for 5 hours.

\subsection{Catalytic testing}

To explore the catalytic activity of Au@zeolites, the synthesized catalysts were utilized for oxidation of cyclohexane. Oxidation of cyclohexane (92.45 mmol per $50 \mathrm{mg}$ of catalyst) was carried out for $2 \mathrm{~h}$ in autoclave at $150{ }^{\circ} \mathrm{C}$, under $1 \mathrm{MPa} \mathrm{O}_{2}$ pressure in the solvent-free system. The results were also compared with those obtained using bare Au NPs, com-ZSM-5, conv-MCM-22, hollow ZSM-5 and MCM-22 prepared by current method.

The products were analyzed by gas chromatography (GC). Flame ionization detector (FID) was used for the analysis of the product sample. AT-100 capillary column (O.D. 1/8" , length = $3 \mathrm{~m}$ ) was used for the purpose. The oven temperature was set at $140{ }^{\circ} \mathrm{C}$. The injector and detector temperatures were $230{ }^{\circ} \mathrm{C}$ and $240{ }^{\circ} \mathrm{C}$ respectively.

\subsection{Characterization}

X-Ray Diffraction (XRD) was performed on a PAN analytical make $\mathrm{X}$-ray diffractometer using Ni filtered $\mathrm{K} \alpha$ radiation from a Cu target $(\lambda=1.54 \AA)$. The sample was scanned between the angles $5-80^{\circ}$ at a scan rate of $3^{\circ} \mathrm{min}^{-1}$. 
The TEM analysis of bare zeolite and zeolite coated gold nanoparticle was carried out on FEI make TecnaiTM G2 U-Twin $(200 \mathrm{kV})$ transmission electron microscope. For TEM analysis, the samples were dispersed in water. $5 \mu$ from the sample was loaded on a carbon-coated copper grid which was dried under vacuum. The solid UV analysis for zeolite samples was carried out in a Varian Cary 5000 UV-vis-NIR spectrophotometer having deuterium lamp (185-350 nm) halogen lamp (350-3300 nm) with R928 PMT detector.

Elemental analysis for gold in zeolite samples were carried out using Thermo Fisher Scientific X Series II (inductively coupled plasma mass spectrometry) ICP-MS. The elemental compositions of the prepared zeolite samples were determined using X-ray fluorescence (XRF). The analysis was done on a Rigaku-ZSX Primus II XRF spectrometer. For XRF analysis, the calcined samples were pelletized using a hydraulic press at a pressure of 15-20 tons. The surface area and pore size were determined based on the amount of $\mathrm{N}_{2}$ that was adsorbed and desorbed at $27 \mathrm{~K}$, using Autosorb-1C (Model: AS1-C, Quantachrome, USA). The micro and meso pore volumes in the material were calculated using density functional theory (DFT). The temperature-programmed desorption of $\mathrm{NH}_{3}\left(\mathrm{NH}_{3}\right.$-TPD) was conducted over $0.10 \mathrm{~g}$ of each sample from $150{ }^{\circ} \mathrm{C}$ to $600{ }^{\circ} \mathrm{C}$ at a heating rate of $5{ }^{\circ} \mathrm{C} \mathrm{min}^{-1}$ while monitoring the thermal conductivity detector (TCD) signals and after saturation with $\mathrm{NH}_{3}$ at $150{ }^{\circ} \mathrm{C}$ for $30 \mathrm{~min}$, the catalysts were flushed with He for $1 \mathrm{~h}$. All of the samples were treated in $\mathrm{He}$ at $600{ }^{\circ} \mathrm{C}$ before the experiment to remove any adsorbed water or organic species. The peak area can be correlated with the amount of adsorbed $\mathrm{NH}_{3}$ based on the pulsed $\mathrm{NH}_{3}$ injection experiment.

\section{Results and discussion}

\subsection{Catalyst characteristic}

Two different sizes $(\sim 20$ and $\sim 35 \mathrm{~nm})$ of gold nanoparticles were prepared and have been characterized by scanning electron microscopy (SEM) (Fig. S1 $\dagger$ ). Fig. S2b $\dagger$ shows the transmission electron microscopy (TEM) image of $\mathrm{Au} @ \mathrm{SiO}_{2}$ proving that gold nanoparticles are coated with silica (shell thickness $\sim$ $400 \mathrm{~nm}$ ), which is the starting material for the synthesis of different zeolites shell. Fig. 1a and b displays TEM images of Au@MCM-22 and Au@ZSM-5 respectively. Contrast in the TEM images (Fig. S3 and S4 $\dagger$ ) clearly suggest that single gold nanoparticle is encapsulated by zeolite nanocapsule (shell thickness $\sim 65 \mathrm{~nm}$ for ZSM-5 and $\sim 33 \mathrm{~nm}$ for MCM-22). We observed reduction in the shell thickness from silica encapsulated to zeolite encapsulated nanoparticles which might be due to the etching of unreacted silica by $\mathrm{NaOH}$ present in the reaction mixture. Further, the TEM images prove that the gold nanoparticles retain its size/shape even after calcination at $550{ }^{\circ} \mathrm{C}$ for $5 \mathrm{~h}$. In addition, the SEM images clearly suggest that Au@MCM-22 and Au@ZSM-5 catalysts possess uniform spherical morphology with a size of about $600 \mathrm{~nm}$ and $400 \mathrm{~nm}$, respectively (Fig. 1c and d). In contrast to gold nanoparticle supported on ZSM-5 (Fig. S5†), SEM image of zeolite encapsulated gold nanoparticle (Fig. 1c and d) showed no gold nanoparticle on the surface, which proves the absence of gold

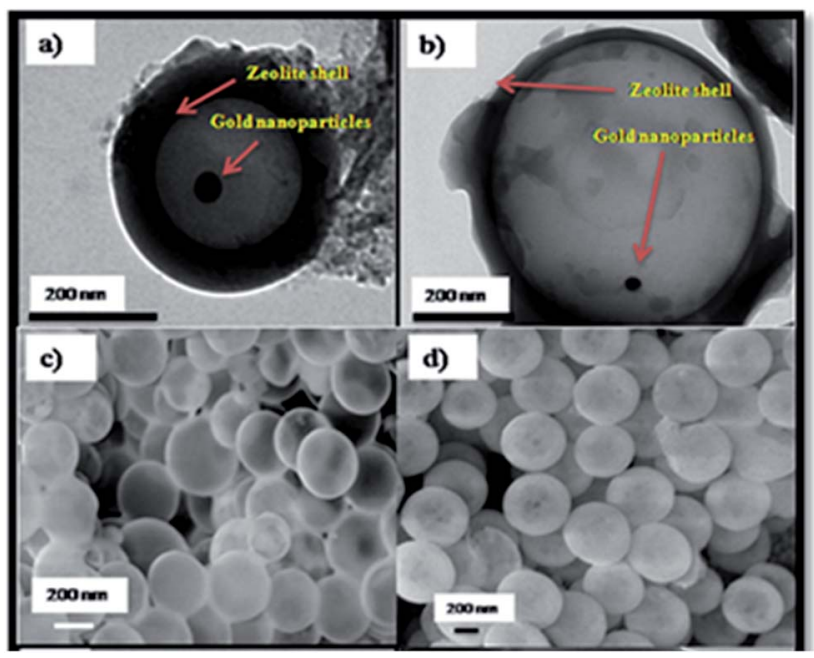

Fig. 1 TEM images of (a) AuaZSM-5, (b) Au@MCM-22. SEM images of (c) Au@ZSM-5, (d) Au@MCM-22 showing gold nanoparticle encapsulated inside zeolite shell.

particles on the exterior surface of zeolite shell. Moreover, the exterior surface morphology of bare zeolites (Fig. S6†) matches with that of Au@zeolites. Fig. S7† presents the TEM images of bare zeolite particles. The hollow cavity (as observed from TEM images) reduces the diffusion hindrance for reactants and presence of single gold nanoparticle in hollow cavity further prevents sintering during catalytic reaction.

The X-ray diffraction (XRD) data (Fig. 2) of Au@ZSM-5 and $\mathrm{Au} @$ MCM-22 possess diffraction peaks ${ }^{32,33}$ of corresponding zeolites matching with previous reports and also with the JCPDS data (JCPDS files 42-0023 and 47-0242). To check the effect of heat treatment on crystallinity of ZSM-5, XRD analysis was also carried out for ZSM-5 dried at $200{ }^{\circ} \mathrm{C}$ (Fig. S15 $\dagger$ ). The analysis suggest that calcination at $500{ }^{\circ} \mathrm{C}$ did not improve the crystallinity significantly. In addition, XRD data of commercial ZSM-5 (com-ZSM-5) and MCM-22 prepared by using reported method (conv-MCM-22) ${ }^{31}$ match with Au@zeolites (Fig. S14†). In summary, XRD data suggests the

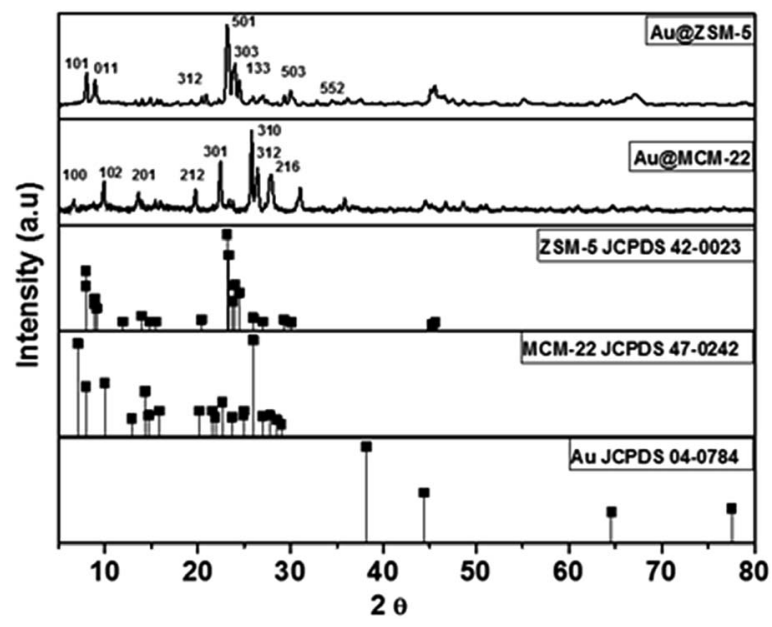

Fig. 2 XRD analysis of Au@ZSM-5 and Au@MCM-22. 
formation of corresponding zeolites. Further, SAED patterns of Au@MCM-22, bare MCM-22 and bare ZSM-5 show the diffraction pattern from planes which match with the corresponding JCPDS data (Fig. S12†). UV-vis spectra (Fig. S8 and S9†) show absorbance around $520 \mathrm{~nm}$ due to SPR effect from $\mathrm{Au}$ for Au@zeolites, confirming the presence of Au nanoparticle. Fig. $\mathrm{S} 17 \dagger$ demonstrates $\mathrm{N}_{2}$ adsorption/desorption isotherms of the zeolites prepared by current method which belongs to type IV isotherm suggesting that they possess both micropores and mesopores. The pore size distributions of all the analysed samples were derived from $\mathrm{N}_{2}$ sorption using density functional theory (DFT) (Fig. S18 $\dagger$ ). All the zeolites prepared by current method possess micropores in the size range of $\sim 5.5 \AA$ which is in accordance with the 10-MR channels. Further Au@ZSM-5, Au@MCM-22, ZSM-5, and MCM-22 also possess mesopores in size of $\sim 30.8,34.5,31.5$, and $33.1 \AA$ respectively. In addition, the surface area of all the zeolites is in the range of $390-421 \mathrm{~m}^{2} \mathrm{~g}^{-1}$ (Table S1 $\dagger$ ). Total pore volumes were determined from adsorbed volume at $P / P_{0}=0.99$ as 0.60 and $0.51 \mathrm{~cm}^{3} \mathrm{~g}^{-1}$ for Au@ZSM-5 and Au@MCM-22, respectively. The zeolites prepared by current method were mesoporous as $\mathrm{NaOH}$ used during synthesis may create mesopores as reported in literature where mesopores $\sim 20 \mathrm{~nm}$ were created..$^{32}$ Additional experiments were performed to investigate the acidity of prepared catalyst using $\mathrm{NH}_{3}$-TPD analysis. Fig. $\mathrm{S} 13 \dagger$ depicts temperature programmed desorption of $\mathrm{NH}_{3}\left(\mathrm{NH}_{3}\right.$-TPD) results of Au@zeolites, bare hollow zeolites (prepared by the proposed method) and commercial zeolites. TPD results clearly show two desorption peaks in which broad peak 1 is attributed to weak acid site which desorbs ammonia around $250{ }^{\circ} \mathrm{C}$, whereas peak 2 is attributed to strong acid site which is centered at $460{ }^{\circ} \mathrm{C}$ matching with several reports. ${ }^{32,36}$ The amount of total acidic sites was calculated (Table 1) from desorption TPD peak area and the total acidity decreases in the following order: Au@MCM-22 Au@ZSM-5 > bare-MCM-22 > bare-ZSM-5 > conv-MCM-22 > com-ZSM-5. The concentration of stronger acid sites was also calculated from the high temperature desorption TPD peak area which is in the following order: Au@MCM-22 > bare-MCM-22 > Au@ZSM-5 > bare-ZSM-5 > comZSM-5 > conv-MCM22. Similarly, the concentration of weak acid sites was calculated from the low temperature desorption TPD peak area and it decreases in the following order: Au@ZSM-5 > conv-MCM-22 > Au@MCM-22 > bare-MCM-22 > bare-ZSM-5 com-ZSM-5. In summary, the catalysts prepared by the current method possess more acidic sites compared to the commercial catalysts.

Table 1 The total acidity of the catalyst

\begin{tabular}{llll}
\hline Sample name & $\begin{array}{l}\text { Weak acidic } \\
\text { site }\end{array}$ & $\begin{array}{l}\text { Strong acidic } \\
\text { site }\end{array}$ & $\begin{array}{l}\text { Conc. of total acidity } \\
\left(\mathrm{mmol}_{\mathrm{NH}_{3}} \mathrm{~g}_{\text {cat. }}{ }^{-1}\right)\end{array}$ \\
\hline Au@MCM-22 & 0.25 & 0.61 & 0.86 \\
Bare MCM-22 & 0.21 & 0.57 & 0.78 \\
Au@ZSM-5 & 0.34 & 0.52 & 0.86 \\
Bare ZSM-5 & 0.17 & 0.4 & 0.57 \\
Conv-MCM-22 & 0.27 & 0.15 & 0.42 \\
Com-ZSM-5 & 0.17 & 0.22 & 0.39
\end{tabular}

\subsection{Catalytic performance}

The spent catalysts retain their spherical morphology with intact zeolite shell as observed from the TEM images (Fig. 3a and b). This clearly suggests that Au@zeolites possesses very high stability under severe reaction conditions. To prove the importance of protection by zeolite shell we calcined unsupported gold nanoparticles and gold nanoparticles supported on zeolite surface and in both cases, gold nanoparticles were found to agglomerate (Fig. S10 and S11†). Fig. 4 shows the conversion and selectivity of cyclohexane oxidation using current Au@zeolites and several control samples. Au@MCM-22 (54.5 mmol) and Au@ZSM-5 (38.9 mmol) showed greater cyclohexane conversion compared to their respective control samples. Cyclohexane conversion decreases in the following order: Au@MCM-22 > goldnanoparticles > MCM-22 > Au@ZSM-5 > ZSM-5 > conv-MCM-22 > com-ZSM-5. It is to be noted that the amount of gold used for oxidation of cyclohexane is 1000 times more than the amount of gold in Au@zeolites. Turn over number (TON) was calculated as millimole of oxidized products per millimole of strong acidic sites and turn over frequency (TOF) as millimole of oxidized products per millimole of strong acidic sites per hour (Table S3 $\dagger$ ). Au@MCM-22 exhibits highest TON and TOF among the analyzed samples, due to presence of higher concentration of strong acid sites (Table 1). We note that, turn over frequency for Au@zeolites and bare zeolites (prepared by current method) was higher as compared to respective commercial and conventionally prepared zeolites.

\subsection{Indicative catalytic mechanisms}

As reported in literature, oxidation of cyclohexane to cyclohexanone and cyclohexanol can undergo via (1) radical-chain autoxidation (2) Franck-Rabinowitch solvent cage, and (3) HaberWeiss cycle mechanisms. ${ }^{37,38}$ Franck-Rabinowitch and HaberWeiss cycle mechanism typically occurs in the presence of solvent and metal ion (e.g. $\mathrm{Co}^{2+}, \mathrm{Mn}^{2+}$, and $\mathrm{Cr}^{2+}$ ) substituted zeolites respectively, and hence, less applicable for the present study. Hence, we have attempted to rationalize the results by focusing on the radical-chain autoxidation mechanism (Scheme 2), which has been shown to be the operational mechanism in most cases. The autoxidation of cyclohexane proceeds through activation of the $\mathrm{C}-\mathrm{H}$ bond via abstraction of an $\mathrm{H}$ atom (step1) forming carbon centered radicals which react with $\mathrm{O}_{2}$ to give peroxyl radicals (step2). The formed radicals reacts further with

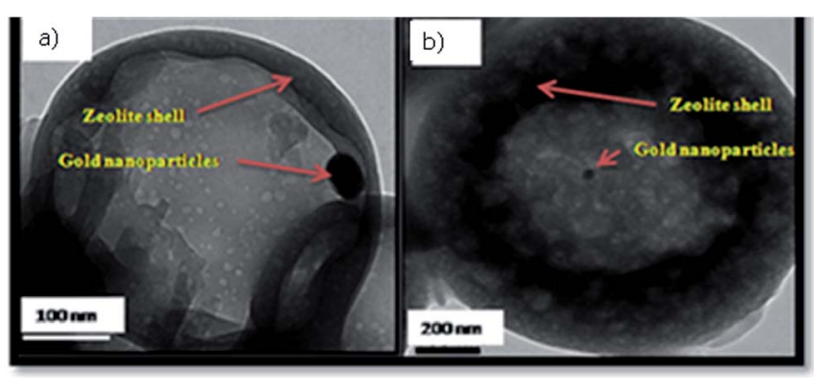

Fig. 3 TEM images of spent (a) Au@ZSM-5, (b) Au@MCM-22 after oxidation of cyclohexane. 


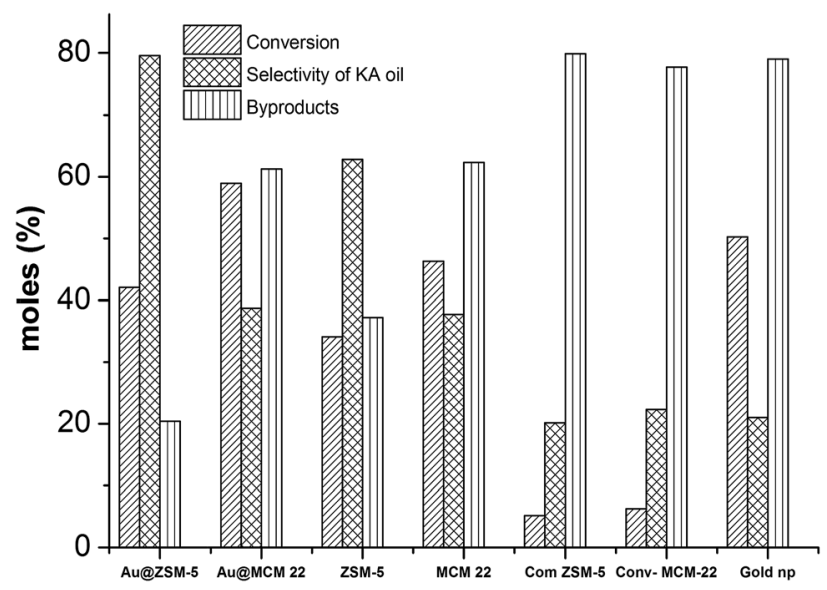

Fig. 4 Conversion of cyclohexane and selectivity towards KA-oil for different catalyst. Amount of gold in case of control experiment was higher (1000 times) than in case of Au@ZMS-5 and Au@MCM-22.

cyclohexane to give cyclohexyl hydroperoxide and another peroxyl radical, thus ensuring propagation of the reaction (step3). Cyclohexanol can be obtained by hydrogenation of cyclohexyl alkoxy radical (step6) after reacting further with cyclohexane. This again results in the formation of carbon centered parent radical which will again react with $\mathrm{O}_{2}$ to give peroxyl radicals thus further ensuring propagation of the reaction. Radical initiators (AIBN and TBHP) ${ }^{38}$ promote the oxidation reaction by decomposing to carbon centered radicals which can either instigate $\mathrm{H}$ abstraction (step1), or can react further with oxygen present in the reaction media to form peroxyl radicals (step2). Au is capable

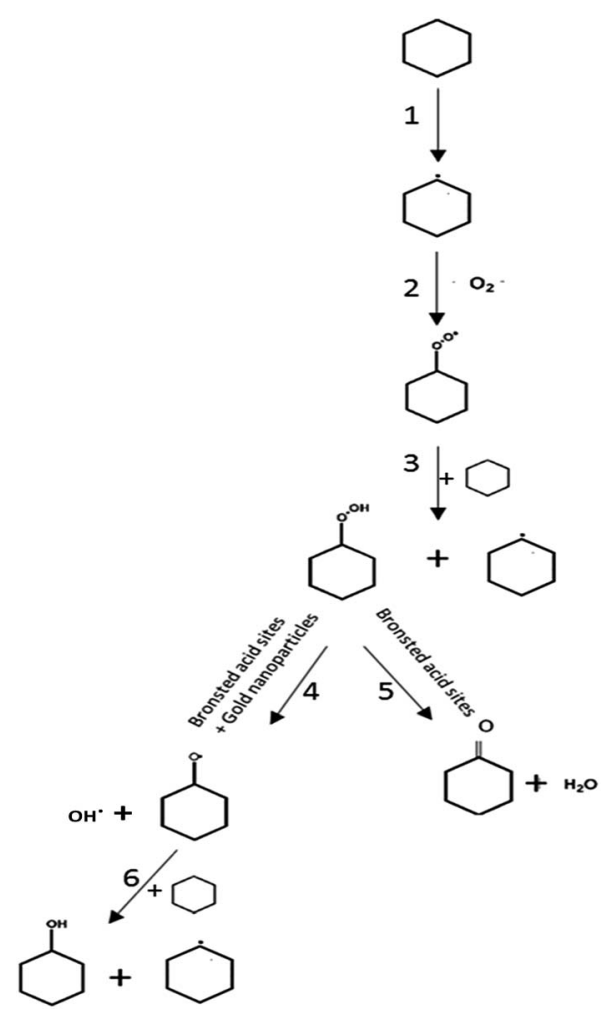

Scheme 2 Radical-chain mechanism for oxidation of cyclohexane. of accelerating the reaction by cleavage of the $\mathrm{O}-\mathrm{O}$ bond of cyclohexyl hydroperoxide (step4) ${ }^{38}$ without the need for initiators. Moreover, Brønsted acid sites present in zeolites also enhances the decomposition of cyclohexyl hydroperoxide ${ }^{39}$ and in addition Brønsted acid sites enhance the formation of cyclohexanone, by dehydration of cyclohexyl hydroperoxide (step5). ${ }^{40}$ No initiator was used for the current reaction while most of the experiments from the literature have initiators.

Overall, we believe that the following factors predominantly determine the conversion and selectivity of the reaction: (1) acid sites present in zeolites, (2) gold nanoparticles, and (3) shell thickness and pore size of zeolites.

\subsection{Rationalizing higher conversion of cyclohexane by Au@zeolites}

We note that since gold and acid sites are capable of accelerating O-O bond cleavage of cyclohexyl hydroperoxide and Au@MCM-22 possesses higher concentration of strong acid sites compared to all the other samples (Table 1), Au@MCM-22 shows highest conversion in comparison to other catalyst samples. Due to the presence of higher concentration of strong acid sites, zeolites prepared by our method showed enhanced cyclohexane conversion in comparison to commercial zeolites. Moreover, gold is protected by zeolite nanoshell against sintering and loss of catalytic activity. It is also noted that we have not added any initiator in current reaction unlike in most of the published reports (e.g. AIBN and TBHP). ${ }^{38}$ We note that the amount (determined by inductively coupled plasma mass spectrometry and X-ray fluorescence, Table S2 $\dagger$ ) of Au present in Au@ZSM-5 (0.012 wt\%) and $\mathrm{Au} @ M C M-22(0.011 \mathrm{wt} \%)$ is very less compared to bare gold nanoparticle catalysts used control experiments. If gold and the bare zeolites (prepared by current method) were acting independently, the conversion due to the Au@zeolite composite is expected to be additive. This additive conversion value would have been 31.5 mmol for Au@ZSM-5 and 42.8 mmol for Au@MCM-22. We note that this additive conversion value is less than that of experimentally measured values of 38.9 mmol for Au@ZSM-5 and $54.5 \mathrm{mmol}$ for Au@MCM-22, suggesting synergistic effect in Au@zeolites composite catalysts. Apart from the above effects we believe that thickness of zeolite shell also can affect the conversion due to mass transfer resistance for the reactive intermediates towards reacting with Au. Shell thickness of Au@ZSM-5 and Au@MCM-22 is $\sim 65 \mathrm{~nm}$ and $\sim 33 \mathrm{~nm}$ respectively and hence, Au@ZSM-5 impose greater mass transfer resistance resulting in lesser conversion. Apart from cyclohexanol and cyclohexanone formation, byproducts (cyclohexyl ester, adipic acid, hexanoic acid, acetic acid, pentanoic acid) were also formed.

\subsection{Rationalizing higher selectivity towards cyclohexanol and cyclohexanone by Au@zeolites}

Gold enhances the cyclohexanol formation by cleavage of $\mathrm{O}-\mathrm{O}$ bond present in cyclohexyl hydroperoxide which makes the reaction more selective towards cyclohexanol formation ${ }^{38}$ (Fig. S16†) in case of Au@ZSM-5 in comparison to bare ZSM-5 and hence increasing overall selectivity towards KA-oil. On the other hand Au@MCM-22 and bare MCM-22 having similar concentration of 
strong acid sites exhibit similar activity towards KA-oil. As no gold is present in commercially and conventionally prepared zeolites, they showed lesser selectivity towards KA-oil in comparison to Au@ZSM-5.

\section{Conclusion}

In conclusion, sinter-resistant monodispersed Au@MCM-22 and Au@ZSM-5 were successfully synthesized via conversion of Au@silica through hydrothermal route. These gold nanoparticle encapsulated by zeolite nanoshell catalysts showed higher activity towards cyclohexane oxidation in comparison to commercial and conventionally prepared zeolites at $150{ }^{\circ} \mathrm{C}$ temperature and $1 \mathrm{MPa} \mathrm{O}_{2}$ pressure. This method can be generalized to assemble various nanoparticles encapsulated by different zeolite shells to cater towards various reactions performed at harsh conditions.

\section{Acknowledgements}

We are thankful to Indian Institute of Technology Kanpur for providing us financial and technical support.

\section{References}

1 J. Oliver-Meseguer, J. R. Cabrero-Antonino, I. Dominguez, A. Leyva-Pérez and A. Corma, Science, 2012, 338, 1452-1455.

2 A. Kongkanand, K. Tvrdy, K. Takechi, M. Kuno and P. V. Kamat, J. Am. Chem. Soc., 2008, 130, 4007-4015.

3 S. Proch, M. Wirth, H. S. White and S. L. Anderson, J. Am. Chem. Soc., 2013, 135, 3073-3086.

4 S. Kundu, V. Maheshwari, S. Niu and R. F. Saraf, Nanotechnology, 2008, 19, 065604.

5 M. Haruta, S. Tsubota, T. Kobayashi, H. Kageyama, M. J. Genet and B. Delmon, J. Catal., 1993, 144, 175-192.

6 S. A. C. Carabineiro, L. M. D. R. S. Martins, M. Avalos-Borja, J. G. Buijnsters, A. J. L. Pombeiro and J. L. Figueiredo, Appl. Catal., A, 2013, 467, 279-290.

7 B. Nkosi, M. D. Adams, N. J. Coville and G. J. Hutchings, J. Catal., 1991, 128, 378-386.

8 T. Mitsudome and K. Kaneda, Green Chem., 2013, 15, 26362654.

9 M. Turner, V. B. Golovko, O. P. H. Vaughan, P. Abdulkin, A. Berenguer-Murcia, M. S. Tikhov, B. F. G. Johnson and R. M. Lambert, Nature, 2008, 454, 981-983.

10 J. Zhao, Z. Zheng, S. Bottle, A. Chou, S. Sarina and H. Zhu, Chem. Commun., 2013, 49, 2676-2678.

11 D. Gajan, K. Guillois, P. Delichère, J.-M. Basset, J.-P. Candy, V. Caps, C. Coperet, A. Lesage and L. Emsley, J. Am. Chem. Soc., 2009, 131, 14667-14669.

12 F. Yang, M. S. Chen and D. W. Goodman, J. Phys. Chem. C, 2008, 113, 254-260.

13 H. Wang, K. Schaefer and M. Moeller, J. Phys. Chem. C, 2008, 112, 3175-3178.

14 A. J. Forman, J.-N. Park, W. Tang, Y.-S. Hu, G. D. Stucky and E. W. McFarland, ChemCatChem, 2010, 2, 1318-1324.
15 S. Wang, Q. Zhao, H. Wei, J.-Q. Wang, M. Cho, H. S. Cho, O. Terasaki and Y. Wan, J. Am. Chem. Soc., 2013, 135, 11849-11860.

16 R. C. B. Scaravelli, R. L. Dazzi, F. C. Giacomelli, G. Machado, C. Giacomelli and V. Schmidt, J. Colloid Interface Sci., 2013, 397, 114-121.

17 U. Schuchardt, D. Cardoso, R. Sercheli, R. Pereira, R. S. da Cruz, M. C. Guerreiro, D. Mandelli, E. V. Spinacé and E. L. Pires, Appl. Catal., A, 2001, 211, 1-17.

18 J. Jae, G. A. Tompsett, A. J. Foster, K. D. Hammond, S. M. Auerbach, R. F. Lobo and G. W. Huber, J. Catal., 2011, 279, 257-268.

19 W. Yao, Y. Chen, L. Min, H. Fang, Z. Yan, H. Wang and J. Wang, J. Mol. Catal. A: Chem., 2006, 246, 162-166.

20 X. Zhou, H. Chen, X. Cui, Z. Hua, Y. Chen, Y. Zhu, Y. Song, Y. Gong and J. Shi, Appl. Catal., A, 2013, 451, 112-119.

21 A. Sakthivel and P. Selvam, J. Catal., 2002, 211, 134-143.

22 E. L. Pires, J. O. C. Magalhães and U. Schuchardt, Appl. Catal., A, 2000, 203, 231-237.

23 R. Zhao, D. Ji, G. Lv, G. Qian, L. Yan, X. Wang and J. Suo, Chem. Commun., 2004, 904-905.

24 K. Nakano, S. A. Ali, H. J. Kim, T. Kim, K. Alhooshani, J. I. Park and I. Mochida, Fuel Process. Technol., 2013, 116, 44-51.

25 K. Mori, T. Yamaguchi, S. Ikurumi and H. Yamashita, Chem. Commun., 2013, 49, 10468-10470.

26 N. Ren, Y. H. Yang, J. Shen, Y. H. Zhang, H. L. Xu, Z. Gao and Y. Tang, J. Catal., 2007, 251, 182-188.

27 E. A. Khan, E. Hu and Z. Lai, Microporous Mesoporous Mater., 2009, 118, 210-217.

28 Y. Deng, C. Deng, D. Qi, C. Liu, J. Liu, X. Zhang and D. Zhao, Adv. Mater., 2009, 21, 1377-1382.

29 S. Li, L. Burel, C. Aquino, A. Tuel, F. Morfin, J.-L. Rousset and D. Farrusseng, Chem. Commun., 2013, 49, 8507-8509.

30 J. Kimling, M. Maier, B. Okenve, V. Kotaidis, H. Ballot and A. Plech, J. Phys. Chem. B, 2006, 110, 15700-15707.

31 Y. Wu, X. Ren and J. Wang, Mater. Chem. Phys., 2009, 113, 773-779.

32 Y.-J. Ji, H. Xu, D.-R. Wang, L. Xu, P. Ji, H. Wu and P. Wu, ACS Catal., 2013, 3, 1892-1901.

33 J. W. Jun, I. Ahmed, C.-U. Kim, K.-E. Jeong, S.-Y. Jeong and S. H. Jhung, Catal. Today, 2014, 232, 108-113.

34 Q. Wang, S. Xu, J. Chen, Y. Wei, J. Li, D. Fan, Z. Yu, Y. Qi, Y. He and S. Xu, RSC Adv., 2014, 4, 21479-21491.

35 M. Zhou, A. A. Rownaghi and J. Hedlund, RSC Adv., 2013, 3, 15596-15599.

36 Y. T. Kim, K.-D. Jung and E. D. Park, Appl. Catal., A, 2011, 393, 275-287.

37 B. P. Hereijgers and B. M. Weckhuysen, J. Catal., 2010, 270, 16-25.

38 M. Conte, X. Liu, D. M. Murphy, K. Whiston and G. J. Hutchings, Phys. Chem. Chem. Phys., 2012, 14, 1627916285.

39 Z. Sun, J. Xu, Z. Du and W. Zhang, Appl. Catal., A, 2007, 323, 119-125.

40 R. Kumar, S. Sithambaram and S. L. Suib, J. Catal., 2009, 262, 304-313. 